\title{
Rural and urban livelihoods, social exclusion and social protection in sub- Saharan Africa
}

\begin{abstract}
This paper shows that with the decline of overall poverty the concern for rising or persisting inequalities and the need for transformative social protection, capable of countering social exclusion and promoting social justice, becomes increasingly relevant to urbanising subSaharan Africa too. It is argued that several parts of sub-Saharan Africa are likely to move towards pro-poor urbanisation and show emerging changes in rural and urban livelihoods. Then the practice of social protection programmes along the rural-urban continuum in subSaharan Africa is examined extensively in order to determine whether these practices align with emerging changes in livelihoods and tackle social exclusion in a transformative way. It is found that the livelihoods of the poor are enhanced and that social inclusion has increased. However, social protection's adaptation to emerging changes in rural and urban livelihoods is still poor and so is social protection's capacity to tackle social exclusion in a transformative way. It is concluded that transformative social protection would require more structural interventions through empowering pressure on the state and innovative decentralisation from the top.
\end{abstract}

\section{Introduction}

This paper argues that with the decline of overall poverty the concern for rising or persisting inequalities and the need for social protection becomes increasingly relevant to urbanising sub-Saharan Africa too. Meaningful social protection interventions need proper understanding of inequalities and the processes of social exclusion that the poor face when organising their livelihoods. That also requires awareness for emerging changes in rural and urban livelihoods. The second section of the paper demonstrates that with declining poverty, concern is shifting from poverty as such to poverty as a distributional issue. Thus, attention for mechanisms through which the poorest are excluded from livelihoods opportunities becomes important. Moreover, from an examination of efficiency and social justice arguments against inequality, transformative social protection comes to the fore as the appropriate approach to counter that exclusion. The third section takes a closer look at the distribution of poverty in sub-Saharan Africa connected to urbanisation. It is expected that before long also sub-Saharan Africa will experience a reduction in rural poverty and a lower-than-average drop in urban poverty. It is explained that social protection programmes need to prepare for that change, which in turn necessitates an understanding of the emerging changes in rural and urban livelihoods that accompany that change. The fourth section reviews a number of social protection practices along the rural-urban continuum in sub-Saharan Africa and discusses to which extent these practices already align with changing rural and urban livelihoods and tackle social exclusion in a transformative way. The final section concludes that social protection interventions in sub-Saharan Africa generally enhance the livelihoods of the poor and that this brings about social inclusion of beneficiaries. However, poor results are established with respect to social protection's adaptation to emerging changes in rural and urban livelihoods, and social protection's capacity to tackle social exclusion in a transformative way. 


\section{From declining poverty to social exclusion and transformative social protection}

\section{Declining poverty and rising concern for inequality, also in sub-Saharan Africa}

World poverty has dropped significantly. In 2013 Olinto et al. (2013, p. 1) jubilantly established on behalf of the World Bank "an unprecedented pace of poverty reduction over the last decades, reducing the number of people living in extreme poverty [in 2010] by more than 700 million”. Between 1981 and 2013 the number of people living on \$1.90 per day - the new poverty line in 2011 purchasing power parity dollars - dropped from 1.9 billion to 0.8 billion. In the same period, the world poverty headcount dropped from $41.9 \%$ to $10.7 \%$ (World Bank, 2017). Projections suggest that today the headcount has fallen below $10 \%$ (World Bank \& IMF, 2016, p.3).

With poverty at an all-time low since the rise of development as a discourse, the concern is shifting from poverty as such to poverty as a distributional issue and an anxiety for persisting or even rising inequality. "While income inequality across countries has receded somewhat in recent years, it has risen within many countries”. “.... [W] ealthier individuals have become wealthier while the relative situation of the poorer segments of the population has not improved” (DESA, 2013, p. 21 and p. 25). At first sight the increased attention for poverty as a distributional issue seemed to refer mainly to middle-income, where the majority of the world's poor (66\% in 2013 : World Bank, 2017) is now living. Populous Asian countries such as China, India and Indonesia where poverty has become less and less an issue of economic growth and increasingly an issue of distribution of the benefits of growth, then stand prominent. A UN High Level Panel referring to these countries concluded that their "social programs need to be greatly enhanced, and subsidy programs need to be much better targeted on the poor" (SDSN , 2012, p.6). This was echoed by DESA (2013, p. 29) stating that inequality rose in many countries that had relatively low levels of inequality in the 1990s, including some large emerging economies such as China and to a lesser extent India.

But at a closer look maintaining that equalities are only a problem of middle-income counties is too simple: the picture is in fact more diverse. DESA (2013, p. 25) refining its statement above states that "trends have been far from universal: as countries have grown and developed, inequalities have increased in many cases, and have declined in some others". For example, in countries like China and India inequality increased but in the majority of Latin American countries inequality declined - Brazil being a point in case, while also some African countries managed to reduce inequality (DESA 2013, p. 29).

Poverty also declined in sub-Saharan Africa, but while poverty dropped spectacularly in East Asia to 3.5\% in 2013 and in South Asia to 15.9\% , sub-Saharan Africa clearly lacked behind with a drop from 54.3\% in 1990 to 41.0\% in 2013 (World Bank, 2017). Today sub-Saharan Africa is the world's poorest macro-region and it is the only macro-region where the poor have increased in absolute number, i.e. from 276 million in 1990 to 389 in 2013 despite considerable annual economic growth of 3.8\% (World Bank, 2017). Moreover, after Latin America, sub-Saharan Africa is also the most unequal macro-region in the world. On the other hand, inequality decreased significantly between 1993 to 2013: the overall Gini-index declined from 0.47 to 0.40 (World Bank, 2017; 2016) hiding again marked differences between countries. Thus, although country data on inequality do not all point at the same 
direction, concern about the distribution of poverty and persisting inequality in sub-Saharan Africa seems also justified.

\section{Concern for inequality matters, the call for social protection}

Concern for the distribution of poverty and increased inequality is based on varied assumptions. Oxfam (2014) offers an efficiency argument when it explains that growing income inequalities weaken a country's potential for sustained economic growth and increase the probability of a sharp and permanent societal cleavage between rich and poor. It adds that high income inequalities reinforce inequalities in health, in education, in life chances and between men and women. This argument is not very different from the rationale the World Bank (2016) provides for its own increased attention for income inequality. It argues firstly, that income inequality determines educational, social and professional opportunities of children, thus creating unequal livelihoods opportunities for the next generation. That is considered a waste of critical resources and thus inefficient. Secondly, income inequality aggravates other inequalities such as in health and life expectancy. Thirdly, it weakens social unity and "creates openings for paranoid populism and religious or political extremism" (World Bank, 2016, p.13). Interestingly however, the World Bank also states that the relationship between income inequality and economic growth is contested and that findings differ on whether or not reduced inequality foster economic growth. To the United Nations on the other hand, this relationship is univocal. DESA (2013, p.73) maintains that "inequality leads to less stable, inefficient economic systems that restrain economic growth and pose a serious barrier to the eradication of poverty. This, in turn, reduces the contribution of economic growth to social development and reduces social mobility”. Underneath DESA's (2013, p. 21) argument to address inequality is both a moral imperative and an efficiency argument of unleashing human and productive potential. Exclusive moral argumentations against inequality depart from principles of social justice, fairness and equity. From Rawls' (1999) transcendental idea of social justice and reasoning of justice on the basis of rational choice theory, Sen (2009) developed an explanation of justice as an actual social choice, bounded by social practice and individuals capabilities and never perfect. In a practicable description of social justice it means that members of a society perform their tasks and are given their due taking into account deservingness in terms of needs and contribution in relation to capability, furthermore assuming that the procedures of distribution of rewards are fair.

In essence the moral or equity argument against inequality rules out an efficiency argument, but in practice the two often walk together as demonstrated above. Moreover, both agree on how to deal with inequality: through social protection. While social policies aim at all members of society, social protection aims to protect its weakest members Social protection programmes that target the poor are becoming increasingly widespread in the development context. They draw inspiration from the idea of the welfare state, promoting and protecting the well-being of its citizens. Different types of welfare state regimes arising from their specific historical context and structure of society (Esping-Andersen, 1990) are all characterised by redistributionist taxation, a transfer of funds from state to citizens through social services and cash welfare benefits, and universality towards all citizens. Social protection embody nowadays two related areas of contestation: universality and whether or not protection should be a public affair. All welfare state discussed by Esping-Andersen (1990) were universal in character and considered social protection a public affair and responsibility. This did not mean that private sectors initiatives could not play a role, but 
usually within the framework of social policies set by the state. Universality can only be guaranteed by the state and not by the private sector which is intrinsically organised for profit and not for equity and social justice. However, in the neoliberal order from the 1990s onwards the welfare state became restructured and universality and the supremacy of the state were no longer self-evident and became contested by more individualistic and market-based principles (Mkandawire 2005). So the contradiction between efficiency and social justice surfaces again with respect to social protection. However, in practice again the two may walk together. For example targeting in social protection, meaning that eligibility to social benefits is limited to particular individuals or groups, is at odds with universalism which prescribes the same treatment for all. But proponents of universality may well regard it as a first step towards universalism, like they also find affirmative action and gender-progressive policies thinkable within a universalistic system (Fischer, 2012; 2016).

\section{Social exclusion and transformative social protection}

Concern for the distribution of poverty and increased inequality also falls back on the notion of social exclusion. Social exclusion in the meaning of individuals or groups being excluded from full participation in the society, emerged as a concept during the restructuring of European economies in the 1980s which was accompanied by rising unemployment and poverty and followed by the neo-liberal restructuring of the welfare state. Thereupon, the concept made its way to the development debate. Kabeer (2000) argued that the concept offers an integrated way of looking at multiple, overlapping disadvantages by focussing on institutional rules, relationships and processes through which access - spatial access included - to livelihoods resources and opportunities are assigned. Kabeer (2000) also linked social exclusion with social policy and protection, not only as a way to countervail exclusion but to point at the exclusionary impact on livelihoods of social policies themselves. Yet, the full scope of social exclusion and its embeddedness in institutions only became apparent when it was linked to intersectionality. The actual practice of social exclusion depends on the background of the individual in terms of class, age, gender, race, culture, disability and other specific characteristics resulting in intersecting social divisions. Intersectionality entails that processes of exclusion are layered, overlapping, sometimes reinforcing, sometimes not, but never reducible to each other (Yuval-Davis 2006). It can best be understood through a layered analysis of the poor's livelihoods: the poor's access to resources and opportunities is the upper layer, the middle layer scrutinizes the power relations and power struggles they encounter, and the bottom layer unravels impeding underlying and intersecting structures (de Haan, 2016, p.5).

According to Devereux and Sabates-Wheeler (2004), social protection can only countervail social exclusion and contribute to equity, social justice and fairness when it aims higher than protecting livelihoods and becomes transformative. A "transformative view extends social protection to arenas such as equity, empowerment and economic, social and cultural rights, rather than confining the scope of social protection to targeted income and consumption transfers" (Devereux and Sabates-Wheeler, 2004, p. 3). Transformative social protection addresses power imbalances but to imagine transformative interventions is to mind about details. Paying labourers higher wages enhance their livelihoods and capabilities; but assisting them in bargaining is empowering and can have positive transformative implications and so are anti-discrimination campaigns if related to training of social protection beneficiaries (Devereux and Sabates-Wheeler, 2004, p. 12). 


\section{Distribution of poverty and urbanisation in sub-Saharan Africa: emerging changes in rural and urban livelihoods}

\section{Poverty, urbanisation and livelihoods}

The distribution of poverty is connected to urbanisation. Poverty rates are falling in both urban and rural areas, but usually they remain higher in rural areas. Worldwide, urban poverty dropped from $20.5 \%$ in 1990 to $11.6 \%$ in 2008 , while rural poverty dropped from $52.5 \%$ to 29.4\% (World Bank \& IMF, 2013, p. 87). As may be expected from the previous section, figures for sub-Saharan Africa are higher than the worldwide averages, i.e. 33.6\% in urban areas and $47.1 \%$ in rural areas. However, by and large rural poverty is declining faster than urban poverty in sub-Saharan Africa too.

Historically, poverty was predominantly a rural phenomenon. But with the developing world increasingly urbanizing poverty is shifting to urban areas: relatively the urban share of the poor is rising. "The poor are urbanizing faster than the population as a whole, reflecting a lower-than-average pace of urban poverty reduction” (Ravallion, 2016, p. 338). Despite regional differences - for example, in Eastern Europe and Central Asia there are signs of a contra-trend of ruralisation of poverty - urbanisation is generally accompanied by a drop in overall poverty. The reason for his is that urbanisation typically goes hand in hand with economic growth, which usually has a poverty reducing effect. Urban economic growth opens new livelihoods opportunities for migrants from rural areas enabling some of them to escape from poverty. Moreover, urban remittances, growing urban markets and less pressure on rural livelihoods opportunities have positive effects on poverty reduction in rural areas. These usually outweigh the negative effects of migration to urban areas, such as declining quality of rural physical and human infrastructure. As a consequence, urbanisation has more effect on raising rural living standards and reducing rural poverty than on reducing urban poverty. The reason for this is that the new urban dwellers are poorer than those already residing there. A number of the newcomers do escape from poverty but those who don't altogether slow down the pace of urban poverty reduction, even though poverty is falling in rural areas and for the population as a whole (Ravallion, 2016, p. 338 and pp. 440-441).

Despite rapid urbanisation in sub-Saharan Africa, Ravallion (2016, p. 484) is of the opinion that its urbanisation process has not been poverty reducing in the aggregate: urbanisation in sub-Saharan Africa has been less pro-poor as elsewhere in the developing world resulting in higher incidences of poverty in urban areas than in the rest of the world. Causes are not directly evident but may have to do, according to the author, with greater regulation of urban labour markets as well as with little overall growth in agricultural productivity. However, recent indications point at a turn in the urbanisation process in sub-Saharan Africa towards more pro-poor growth as meant by Ravallion (2016). Agergaard (2016, p.21), considering the findings of the RurbanAfrica research programme, provides evidence that assertions about the "disconnect between on the one hand an overwhelmingly 'traditional' agricultural sector that fails to support structural transformation in rural development, and on the other hand rapid urbanisation rates that rather than reflecting economic growth are a major cause of increases in urban poverty and the growth of slums” are no longer tenable. Departing from case-studies on livelihoods in hot spot rural areas - both in low- and middle-income countries - where vibrant agricultural transformations are happening, supplemented by case-studies on urban growth and urban livelihoods in primate cities and secondary towns, the RurbanAfrica 
findings are particularly valuable in imagining what is on the horizon in sub-Saharan Africa with regard to emerging changing livelihoods opportunities, but also to new social exclusions.

Agergaard (2016, pp. 13-24), explains that agricultural transformations are driven by domestic, regional as well as international demand and external investments in land. These have both livelihoods enhancing and excluding effects: sometimes land tenure arrangements become more flexible and local farmers' access to land improves, sometimes rising land prices oust local farmers, excluding them from an agricultural livelihood. Improved accessibility and connectivity through new roads and ICT infrastructure improve farmers' access to markets and their bargaining position. Rising demand for wage labour create new rural livelihoods for seasonal labour migrants. Multiplier effects on the local economy very much depend of the type of crop. Perishable crops like vegetables - requiring dedicated harvesting, handling and transport - rather than industrial crops like palm oil contribute to the local economy in terms of diversification, retaining added value and local reinvestments in processing and thus to the rise of non-agricultural livelihoods and the growth of rural centres and small towns. Mobility is increasing into every direction and contributing to diversification of income sources and more secure livelihoods. But mobility also engenders new exclusions: one person moving to access new livelihoods opportunities relegates another household member to immobility, compelled to take care of the children, the house and the plot (Steel et al., 2017 forthcoming). Migration is no longer a one-way flow from rural to urban, but has turned into a chain of mobilities in which rural and urban livelihoods interact on a movement continuum. Importantly, migrants to urban areas have become a diverse group in terms of age, sex, wealth status and reasons for migrating. Moreover, they are increasingly interested in organising a permanent urban livelihood. This means they will invest in the city, possibly at the expense of their rural home area particularly if there the investment opportunities in land and rural livelihoods are scarce (Agergaard 2016, pp. 22-23). Though rural-urban migration is salient, natural increase of the urban population itself is steadily causing urban growth too. Urban-born residents in search of cheaper - un-serviced - peripheral land for incremental house construction, are the main drivers of the physical expansion of urban spaces into surrounding areas (Andreasen et al. 2016). Recent migrants, on the contrary, are attracted to more central locations in the city which offer a large spectrum of - and concomitant struggle for - livelihoods opportunities. They move from one short-term livelihood activity to another and multitasking stretched over different locations and within short time frames. Urban transportation systems are essential for successful urban livelihoods. Informal markets encroach onto the roads and transport upgrading may disrupt such trade and destroy livelihoods (Esson et al., 2016). The same goes more and more for ICT infrastructure and mobile phone and even smart phone connectivity. Strikingly, access to smart phones connectivity already produces new exclusions of livelihoods opportunities (Steel et al., 2017 forthcoming). Water and sanitation are also considered vital by all urban resident to sustain their livelihoods (Agergaard 2016, p. 20). In this respect Waters (2016, p.46) concludes that access to livelihoods opportunities as land and housing and supporting services like infrastructure and community facilities ultimately is the outcome of a livelihoods power struggle.

\section{Urbanisation and transformative social protection}

The RurbanAfrica research programme demonstrates that parts of sub-Saharan Africa are moving towards economic growth and urbanisation as pro-poor as determined by Ravallion (2016) for other parts of the developing world. A drop in overall poverty, rising rural living 
standards and reducing rural poverty, a lower-than-average drop in urban poverty and therefore a rising relative urban share of the total poor, are on the horizon in sub-Saharan Africa. This necessitates adjustment of social policy because social protection programmes were for long mainly directed to rural areas. Worldwide, the coverage of social protection is lower in urban areas compared to rural areas. On average, $21.3 \%$ of the urban population in low and middle income countries is covered by some form of social protection; in rural areas this is $27.7 \%$. In terms of reaching the poorest households, the coverage is $16.6 \%$ in urban areas, which is lower than the $23.4 \%$ in rural areas. The coverage of social protection among the poorest in sub-Saharan Africa is exceptionally low and again lower in urban areas (8.6\%) than in rural areas (10.1\%) (Gentilini, 2015, pp. 41-43).

Yet, Parnell (2016) claims that under contemporary neoliberalism the challenge of making cities fairer has never been bigger. McGranahan et al. (2016) explain this further and argue that a growth-first-than-distribute strategy for urbanisation risks social exclusion to become entrenched and difficult to reverse when prosperity increases: once engrained inequality will reproduce itself. They point, like (Agergaard, 2016, p.28), at city governments hostile to rural migrants wrongly considering them poor, criminal, illegal and overburdening urban services. Spatial exclusion is the result; not because migrants are physically kept out of the city, but because they are not planned for on equal terms. As a result official regulations block informal livelihoods, thwart informal housing, drive residents back on expensive private water provisioning and poor sanitation: in sum inflict spatial exclusion. According to Parnell (2016), a fairer city and thus transformative social protection would imply striving for livelihoods supportive infrastructures as well as institutional adaptation to participation in the urban making by urban residents and recent migrants irrespective of their gender, race, cast, class, origin or cultural identity. McGranahan et al. (2016, p.17) add that it should counter overt discrimination as well as impeding underlying structures creating disadvantages. They propose supplementary bottom-up and top-down approaches: the former through the empowering pressure on the state of organizations of residents and informal sector workers, the latter through decentralisation encouraging participatory innovations.

\section{Social protection practices along the rural-urban continuum in sub-Saharan Africa}

\section{Social protection practices}

Though sub-Saharan Africa shows the lowest coverage in social protection, there are some interesting practices along the rural-urban continuum to review.

The Productive Safety Net Programme (PSNP) of Ethiopia is one of the biggest and one of the oldest social protection programme in sub-Saharan Africa. PSNP provides food and cash transfers to rural beneficiaries as well as rural employment through public work programmes. These labour-intensive programmes contribute simultaneously to the expansion of social services infrastructure and to the rehabilitation of degraded areas, for example by constructing terraces on hill slopes. PSNP does not only aim to relieve chronic or seasonal food insecurity, but also wants beneficiaries to build their assess, strengthen their livelihoods and graduate out of poverty (GFDRR et al., 2013). The number of PSNP target regions doubled from four in 2005 to eight in 2014 and the programme now covers most of the country. In each region, food insecure communities are identified on the basis of food insecurity records of the recent past. Within these communities chronic food insecure households are targeted, as well as 
households that have suddenly became food insecure or that are without any family and other social support. Additional target criteria are household assets such as land size and quality; income from non-agricultural activities and remittances; family size; and number of dependents in the household (World Bank, 2011, p. 6). Original critique on PSNP indicated that its targeting caused additional exclusion of livelihoods. Firstly, the programme's geographical targeting facilitated preferential treatment of areas where political support for the government is strong. Strongholds of the ruling coalition were favoured, while in the beginning, in particular in Amhara Region, large numbers of the poorest households were excluded. Elsewhere supporters of the opposition were not targeted. Secondly, the government's ambition to graduate all beneficiaries into food security within five years resulted in the selection of households capable of graduating rather than very food insecure households. This also explains some of the problems in Amhara Region. Thirdly, communitybased targeting is sensitive to bias. Community task forces, "comprising men and women who often occupied important positions in the community, identified, and later ranked, households meeting the criteria.” (World Bank, 2011, pp. 6-7). This may lead to extremely effective targeting, but is open to favouritism too. Following the critique, important improvements in targeting mechanisms were implemented to avoid exclusionary practices by the programme itself. Moreover, the programme should be applauded for its determination to acknowledge signals of exclusion even if brought forward by independent evaluators (Devereux et al., 2006; GFDRR et al., 2013; Berhane et al., 2013). PSNP shows a continued interest in determining exclusion errors, i.e. not only determining whether beneficiaries were rightly included in the programme, but also finding out how many of the non-beneficiaries were wrongfully excluded. In addition, analysis of livelihoods showed that the programme is quite effective in reaching female-headed households. Despite their fair representation researchers affirmed that women faced serious difficulties in combining the conditions for participating in public works with their domestic chores (Berhane et al., 2013, p. 2). Yet, Ethiopia's poor are not out of the danger zone. Despite improved food security in previous years, the 2015-2017 drought demonstrates that this is a battle not yet won. Nevertheless, the programme enhanced households' asset portfolios and there are signs that targeted households improved their access to health and education, demonstrating the broader developmental effects of the programme. (GFDRR et al., 2013; World Bank, 2011, pp. 6-25). On the transformative side, however, success is limited. At the community level potential power struggles are countered by offsetting favouritism and exclusion of political opponents. But the biggest handicap of PSNP - and social protection in general in Ethiopia - is the authoritarian state that drives it. Strive for fairness and justice is entirely driven from above and there is very little room for upward participation that would facilitates transformative empowerment, ref. the way campaigns of local NGOs were curtailed, even for relatively uncontroversial issues such as the rights of women and children, reducing them to bare service deliverers (Devereux, 2010, p.14) and the way discontent with the city expansion of Addis Ababa was oppressed in 2016.

Launched in 2008, Livelihood Empowerment Against Poverty (LEAP) has become the flagship of the Ghana National Social Protection Strategy, which also comprises a health assurance scheme, free maternal and child health care, free compulsory basis education, free school feeding, labour intensive public works, fertilizer subsidies, electricity cross subsidies and a contributory pensions scheme. Because at the start of the programme the bulk of poverty was located in rural areas, LEAP had a rural focus which was gradually extended to a countrywide coverage. LEAP consists essentially of cash transfers to very poor households, in particular those with orphans or vulnerable children, elderly and people with extreme disabilities. Cash transfer are conditional on (free) enrolment in the National Health Insurance Scheme, because the poor tend to underutilize health services. A comprehensive evaluation 
focussing on rural beneficiaries (Handa et al., 2014, pp. 27-28) shows that LEAP does not have any effect on improved consumption. This is primarily caused by the irregularity of cash transfers, while consumption is driven by permanent income. But households debts decreased and savings went up. There are also indications that the use of preventive care health services has improved. Moreover, child morbidity is declining. LEAP's impact on schooling is also a success: access to secondary schooling increased and on all levels of schooling fewer days are missed and less grades are repeated. LEAP cash transfers successfully enhance rural livelihoods: poor households eat better and spend more on education, without eating into their assets or entering into new debts On the transformative side, LEAP achieved some successes. Female headed households were able to increase access to and control over resources such as labour and land, productive assets and profits. Also women heading households were more empowered and the position of women in men-headed households improved. Unfortunately, gender norms did not change yet (OPM, 2013, pp. 34-49). LEAP's achievement in countering social exclusion and promoting inclusion was also established: beneficiaries were able to return to social networks that require monetary contributions or some solvability, such as extended family risk sharing arrangements, labour farming groups and saving groups (OPM, 2013, p. iii). The amount of credit extended by beneficiaries to others increased as well as the value of gifts received (Handa et al., 2014, p. ii).

South Africa has the biggest social protection programme in sub-Saharan Africa and it covers the whole country. Following the poverty headcount at national poverty line, 53.8\% of the population was poor in 2010, the majority living in rural areas. Poverty levels were almost twice as high in rural areas (77.0\%) than in urban areas (39.2\%) (World Bank 2017). South Africa uses around $15 \%$ of its gross domestic product for social spending and subsidies, as compared to 9\% for Ethiopia. Social protection in South Africa consists of non-contributory schemes for the elderly, the disabled, foster children and poor families with children. In addition, there are supplementary cash and in-kind transfers in particular for older persons and others in distress not benefitting from another social grant. The number of beneficiaries receiving social grants in South Africa doubled from almost 8 million in 2004 to 15.8 million in 2014, mainly due to the expansion of cash transfers to children and elderly (Inchauste et al., 2015, p 8). Around one quarter of South Africa's population receives some sort of social grant; for $22 \%$ of the households it is even the main source of income (ILO 2016). "In many rural areas, social grants are the main sources of income; this is less true in urban households, where a higher proportion of income comes from formal/salaried work" (Hagen-Zanker et al., 2011, p. 11 ). Not only the scale of social protection in South Africa is impressive; it is part of an overall progressive system of taxation and social spending, that manages to reduce inequality on a scale that is the largest achieved in sub-Saharan Africa. With a Ginicoefficient of 0.77 at market income in 2011, inequality in South Africa is amongst the highest in the world. However, it falls to 0.69 after taxes and even to 0.59 after taxes plus social spending including health and education (Inchauste et al., 2015, pp. 45-49). Much of South Africa's social protection system can be described as transformative in intent, not in the least because the system is citizen-driven, i.e. a central role in the struggle for social protection and social justice is driven by social activists, resulting "in hundreds of strikes and service delivery protests every year” (Devereux, 2010, p.13). Thus, in practice the transformative strength of South Africa's social protection is a matter of continuous contestation. This is demonstrated by a pioneering livelihoods study that uncovers intersecting exclusionary processes in the operations of the Foster Care Grant and the Child Support Grant with respect to a group of extremely vulnerable child-headed households in the Ibhayi township of Port Elizabeth (van Dijk 2008). The study refutes the general believe that orphans of the AIDS pandemic are taken into the households of relatives. On the contrary, many 
minors without parents or with a seriously ill parent continue to live together as a household, sometimes attended at a distance by relatives or neighbours. Their access to livelihoods resources and opportunities is extremely limited: child-headed households often live in shacks which used to belong to their parent(s) and they do all kinds of piece jobs, including criminal activities and prostitution. Only some child-headed households are really supported by relatives or neighbours. Most do not receive any support at all, or are even misused and abused. Neither are they visited by social workers or are supported by one of the child grant programmes. If social workers intervene, it is usually to break up the household so that younger children will be fostered in other households. Alternatively, an adult will move in to take over control. Usually these interventions do not match with the needs and wishes expressed by the children in question. On paper the child grant programmes would come in useful for the livelihoods of child-headed households, but in practice they find it very difficult to access grants. Youngster heading households of children are too young to legally apply for a grant although they were eligible. They could apply with the help of a mentor, or rather a mentor could apply on behalf of them. But that causes problems about whether the grant is spent on the children at all, and if so whether they have any say in how it is spent. When coming at the age of 18, youngsters responsible for these households still need assistance to find their way through the bureaucracy. In this way, the study illustrates effectively the power struggles about the access to livelihoods resources between children on the one hand and relatives, neighbours and social workers on the other hand. In general, these power struggles end in further exclusion of the child-headed households. Furthermore, the study convincingly uncovers underlying and intersecting impeding structures in which exclusion is embedded. Many youngster are aware of the grants programmes and their legal entitlement. They do not only loose the power struggle with relatives, social workers, or other adults to access these grants. But they are also hampered by generational constructions that prevent them from taking action. Generational constructions are shared believes and ideas that prescribe how children should behave and communicate with seniors. Generational constructions also inform the behaviour and expectations of adults, including social workers and other government agents, about what children can do and cannot do. Generational constructions result in a low sense of agency of youngsters and in inability to effectively seek formal and informal support. Children do not expect to be taken seriously and therefore do not bother to contact social workers and their department (van Dijk, 2008, pp. 224-243). Further, exclusion on the basis of age - embedded in generational constructions - intersect in this case with habitual exclusionary processes in South Africa based on language, race and class. For example, Hopkins et al (2016, p. 23) note that though social protection is universal in South Africa, migrants have difficulties in accessing grants for which they are eligible because of language barriers.

Moving further on the rural-urban continuum social protection programmes in the slums of Nairobi (Gentilini, 2015, pp. 123-130) show how difficult it is to target the poor and their livelihoods in large cities. Heterogeneity in slums is considerable, making it difficult to use administrative boundaries to delimit the target population. But also community-based targeting is challenging given the fluid nature of communities and the spatial mobility of dwellers. Urban poor try to access livelihoods opportunities dispersed over a manifold of activities and locations. Some level of programme exclusion errors seems therefore inherent to urban social protection. Also monitoring proves difficult because the poor tend to move in and out of poverty frequently. The Nairobi programmes primarily aim to improve livelihoods security for the poorest through better access to food and consist of unconditional cash transfers. Household food security is enhanced considerably due to the programme. Moreover, HIV positive beneficiaries are able to resume their anti-retroviral treatment for 
which a regular and adequate diet is a prerequisite; many of them could not afford that before the programme. Use of the mobile money transfer system M-Pesa proves extremely successful. All transactions are done electronically and beneficiaries consider it also more discrete and safe than cash payments. However, some beneficiaries do not own phones and borrow them. These people are sometimes unaware of information sent around by the programme staff and even anecdotal evidence of extortion from phone owners is reported. Alongside these signals of exclusion by the programme itself, social inclusion was established too. "Beneficiaries had incurred less debt, resorted less to removing children from school, and reduced engaging in transactional sex..... The regularity of the transfers was an incentive for half of the beneficiaries to participate in informal savings groups... In some cases .... recipients could lend to non-recipients. This situation had a positive impact on informal sharing systems, in which households are supposed to pay back the support received in time of need. The cash transfers restored the payback capacity of previously indebted households, reinserting them into these informal mutual-help systems” (Gentilini, 2015, p. 128).

Following the success of its PNSP, Ethiopia has recently embarked upon a Urban Productive Safety Net Programme. "Ultimately seeking to support over 4.7 million urban poor in around 972 cities and towns, the first phase project will provide support to 604,000 beneficiaries in 11 major cities” (IDA, 2015, p.43). The programme consists of conditional and unconditional cash transfers, support to access livelihoods opportunities, and institution building for effective delivery. Beneficiaries will receive transfers accompanied with life skills training and coaching towards self-employed livelihoods and wage employment. The transfers are conditional depending on the beneficiaries participation in public works programmes, which can range from small-scale infrastructure to urban greenery development and environmental and other services projects. However, beneficiaries will set their own number of days to be spent on public works in order not to forego other income opportunities. Therefore, the daily conditional transfer will also be lower than the average wage rate for unskilled work. The transfers are also conditional on meeting obligations in an accompanying livelihoods development training programme, i.e. trainings on financial literacy like how to open a bank account, planning, budgeting and saving. Moreover, the training includes soft skills such as attitude and expectations at work and business and workplace readiness. In the second phase, livelihoods support continues aiming to increase income from either self-employed livelihoods or wage employment. Depending on the beneficiaries' choice the focus is on either starting a business, increasing the profitability of an existing business, on gaining access to wage employment or on moving from low- to higher-wage employment. Unconditional income support will be provided to the elderly and disabled, street children, homeless and beggars. Additional services such as access to shelter and healthcare, counselling, and reunification with their families will address the specific needs of these groups. Special consideration is also given to women's vulnerable position in urban areas (IDA, 2015, pp. 9-32). Citizens' engagement and empowerment beyond participation of beneficiaries in the monitoring and evaluation of the programme itself, is not on the table. The programme's appraisal document expresses concern with public works subprojects involving involuntary resettlement, physical relocation, loss of assets or loss of access to assets, land expropriation and restriction of access to communal land. Regrettably, the trust the donors put in preventive and mitigating measures, legal procedures, compensation and community engagement (IDA, 2015, p. 33) turned out to be pretentious in the light of the 2016 oppression of discontent with urban expansion.

\section{Discussion}


In section 2 and 3 it was argued that a drop in overall poverty, reducing rural poverty and a lower-than-average drop in urban poverty - resulting in a rising urban share in total poverty can also be expected in sub-Saharan Africa. Below it is discussed whether current social protection practices are prepared for this. Two themes that stood prominent in the previous sections will guide this discussion: firstly social protection's adaptation to emerging changes in rural and urban livelihoods, and secondly, social protection's capacity to tackle social exclusion in a transformative way.

Evaluations of practices in rural areas demonstrate that transfers in cash and in kind and public work programmes do improve the poor's livelihoods, in terms of consumption and food security provided that transfers and payments are regular and reliable. Broader effects with regard to livelihoods enhancement, such as increase in assets and improved health and education and better access to these services, are also documented. However, very little resounds from emerging changes in rural livelihoods; worse still, little resonates from the rural context at all. Generally, programmes depart from inventories of the poor's food security and health situation and fail - with the exception of Ethiopia's rehabilitation of degraded areas - to incorporate local livelihoods constraints and opportunities that would make protection interventions more context-specific and thus effective. Especially with a view on emerging changes in rural livelihoods this asks for more attentiveness and anticipation to changing land tenure, deteriorating traditional livelihoods and proletarisation, but also a keenness to benefit from expanding new agricultural livelihoods opportunities and rising nonagricultural livelihoods in emerging rural centres and small towns.

That mobility is increasingly driven by diversification of income sources and interactions of rural and urban livelihoods rather than simply by despair, remains largely unnoticed in social protection. Urbanisation is equated with growing urban poverty and growing slums. Though it is acknowledged that urban poor are mobile in organising their livelihoods, interventions do not bank on connections between urban and rural livelihoods. Mobility is primarily regarded as a coverage risk and complicating the targeting and monitoring of interventions. In general, migrants risk being ineligible for social protection because universality is not guaranteed and even if that is the case they face difficulties as was shown for South Africa. Many schemes are geographically bounded and migrants risk deregistration when moving. On the positive side, the use of mobile money transfers systems for cash transfers such as M-Pesa, matches well the mobile livelihoods of urban poor. Urban contexts offer a conducive environment for e-payments, including ample network connectivity, large coverage of mobile phone agents, and familiarity with the technology. Mobile phones can also improve social networks and urban-rural linkages as they allow money to be sent and received (Gentilini, 2015, pp. 129). LEAP in Ghana has even recently embarked upon a nationwide biometric e-payment system to replace on the spot cash payments. After completing the selection process, which still includes geographical targeting and on the spot household surveys and interviews, the household member who takes money on behalf of the household might be able in the future to cash the grant wherever the household's livelihoods activities dictate.

While still in their infancy the practice of social protection in large cities would gain by realising that urban-rural linkages are rapidly changing, that not all migrants are poor, that they are increasingly interested in organising a permanent urban livelihood and they are attracted to more central locations in the city which offer a large spectrum of livelihood opportunities. Urban social protection interventions are aware of the heterogeneity among migrants and that their livelihoods require mobility, but do not adapt their interventions to 
that. With the exception of Ethiopia, training to raise the employability of the poor in wage employment or self-employed livelihoods, provision of day care or investments in the prevention of violence or health risks (Gentilini, 2015, p 13), are lacking. This brings us to the missing link between social protection practices and other urban social policies including urban planning. For a genuine enhancement of the poor's livelihoods, urban social protection programmes should be able to connect the poorest to urban planning interventions. The importance for their livelihoods of urban transportation systems, ICT infrastructure and mobile phone connectivity has been indicated. Progress can also be expected from facilitating the poor's access to social housing or effective delivery mechanisms of land for informal selfbuilding.

Without exception, social protection programmes are keen to put appropriate targeting mechanisms in place in order to prevent that the most vulnerable are excluded from their efforts. Exclusion of the beneficiaries lurks in cases of elite capture, i.e. where dominant political groups have the opportunity to disregard opponents or powerful haves ignore powerless have-nots. Geographical and community targeting enable this mode of exclusion. In cities, social protection intervention risk to be captured by non-poor too. In particular urban planning, the provision of services and slum upgrading schemes are vulnerable to middleclass capture. But more hidden forms of exclusion lurk too. The extreme poor are difficult to locate and to grasp. Not used to voicing their interests, they are easily overlooked. That is why self-targeting seems inappropriate to grasp the extreme poor. Self-targeting arrangements are often successful in preventing the richer strata to take advantage, simply because they have access to better income opportunities. As a result the opportunity costs for example of a public works project are too high for this group. But self-targeting itself is not capable of reversing the poor's powerlessness and self-exclusion. Fortunately, with respect to countering social exclusion it has been clearly established that social protection interventions can be effective and contribute to inclusion. Enhancement of livelihoods is commonly followed by entry or return (in)to social networks that require an ability to pay such as saving and risksharing groups. Moreover, children returned to school. Thus in general, beneficiaries managed to restore or enhance their participation in society.

But in order to become truly transformative, social protection needs to strive for more structural interventions through mutually reinforcing bottom-up and top-down approaches, i.e. empowering pressure on the state from grass-roots organisations and innovative decentralisation from the top (McGranahan et al. 2016). Decentralization accompanied by strengthening local governance and community participation will help to better understand urban poverty challenges and make social protection interventions more transformative. The establishment of decentralized coordination platforms, where bottom-up and top-down meet, where urban policies are aligned with social protection interventions and vice-versa and where the spatial component of social exclusion is acknowleded, would be a powerful step in the direction of countering social exclusion (Gentilini, 2015, p 129). These platforms should strike a locally appropriate balance between voluntarism and regulation, remembering that already non-enforcement of existing inappropriate regulations can be an important means of de facto support to the poor (Palmer and Simon (2016, pp. 156-159). Hence, in the end much depend on the developmental character of the state and its commitment to a social contract with the citizens on the one hand, and on citizens' participation on the other hand. This explains the relatively advanced and progressive social protection programmes discussed above in Ethiopia, Ghana and South Africa. "The main reason why most African countries have inadequate social protection systems is that their governments are not seriously committed to providing these forms of protection, and their citizens are not yet mobilising to 
demand their human right to social security. Only when governments and citizens prioritise social protection will poor and vulnerable Africans get the comprehensive social protection systems that they so desperately need" (Devereux, 2010, p.17).

\section{Conclusion}

This paper argued that concern about the distribution of poverty and persisting or increased inequality despite prospects of economic growth is also justified for sub-Saharan Africa. Concern for the distribution of poverty and persisting or increased inequality was further explained by discussing efficiency and social justice or equity arguments against social inequality. It was demonstrated that in practice they walk together and support social protection as a mean to counter inequality, despite controversies over universality and the role of the state. It was further argued that in essence inequality is caused by social exclusion of the poor from decent livelihoods and that only transformative social protection is capable of countervailing that and contributing to equity, social justice and fairness.

Not surprisingly current changes in the distribution of poverty occur within the context of urbanisation. Doubt was raised whether urbanisation in sub-Saharan Africa is as poverty reducing and pro-poor as elsewhere in the developing world. However, signs that point at a turn were established: several parts of sub-Saharan Africa show emerging changes in rural and urban livelihoods and are moving towards pro-poor urbanisation. This means that a drop in overall poverty, rising rural living standards and reducing rural poverty, a lower-thanaverage drop in urban poverty and therefore a rising relative urban share of the total poor, are on the horizon in sub-Saharan Africa too. Subsequently, the emerging changes in rural and urban livelihoods were further discussed as well as the contours of transformative social protection in the context of urbanisation.

Then the practice of social protection programmes along the rural-urban continuum in subSaharan Africa was examined extensively. It was found that generally the livelihoods of the poor were enhanced and that these enhanced livelihoods for their part brought about social inclusion of beneficiaries. Programmes were also increasingly sensitive to exclusionary practices they themselves generate. These positive outcomes were somewhat overshadowed by poor results with respect to social protection's adaptation to emerging changes in rural and urban livelihoods, and social protection's capacity to tackle social exclusion in a transformative way. Very little resounded from emerging changes in rural livelihoods; mobility was primarily considered a coverage risk instead of potentially improving livelihoods security; and a broader perspective on enhancing livelihoods of the urban poor, including inclusion in urban planning, was lacking. Finally, transformative social protection would require more structural interventions through empowering pressure on the state and innovative decentralisation from the top. 